\title{
Interaction of calcite with rare earth hydrothermal fluids
}

\author{
AdRIENN MARIA SZUCS ${ }^{1,2}$, Claire O'DONNELL ${ }^{1}$, SEANA \\ DAVIS $^{1}$, AleXANDRA STAVROPOUlOU ${ }^{1}$, JuAN Diego \\ RODRIGUEZ-BLANCO ${ }^{1,3}$ \\ ${ }^{1}$ iCRAG, Department of Geology, School of Natural \\ Sciences, Trinity College Dublin, Ireland, \\ ${ }^{2}$ szcsa@tcd.ie; 3J.D.Rodriguez-Blanco@tcd.ie
}

Separation processes of rare-earth elements obtained from carbonatite deposits are usually inefficient, expensive, and environmentally aggressive. Therefore, finding alternative ways and/or sources to reduce the costs and avoid environmental damage is crucial, as the global demand for rare earths will be continuously increasing. This new knowledge will require a deeper understanding of the mechanisms that control the interaction of rare-earth bearing hydrothermal fluids with minerals in order to learn how these elements are concentrated in carbonatite deposits. In this study, we assess the ability of calcite -a common mineral in carbonatites- to uptake rare-earth elements from hydrothermal fluids.

The fate of rare earths (alone and in combination) during the interaction of hydrothermal fluids with calcite was investigated by carrying out batch experiments at controlled temperatures. For this purpose, calcite crystals were placed in contact with rare-earth bearing solutions of different concentrations (few ppm to $10 \mathrm{mM}$ ) at a range of temperatures $\left(21-220{ }^{\circ} \mathrm{C}\right)$. Solid samples were collected at elapsed times up to 6 months and characterised with powder X-ray diffraction (XRD), laser ablation inductively coupled plasma mass spectrometry (LA-ICP-MS), scanning electron microscopy and energy-dispersive X-ray spectroscopy (SEMEDS).

Results revealed that calcite is able to uptake the rareearth elements from solution even after short reaction times, and the kinetics and mechanisms of uptake are strongly dependent on temperature and also on the concentrations of rare earths in the fluid phase. While at lower temperatures and concentrations the diffusion into the calcite structure is the primary mechanism of uptake, higher temperatures strongly favour the formation of rare earth bearing surface precipitates and pseudomorphic mineral replacement reactions. These solvent-mediated transformations are usually multi-step, involving complex crystallisation pathways that depend on the composition of the hydrothermal fluid and the reaction temperature, variables that control polymorph selection, crystal chemistry and morphology of the surface precipitates. 